\title{
MULTIPLE ACCESS POINTS WITHIN THE ONLINE CLASSROOM: WHERE STUDENTS LOOK FOR INFORMATION
}

\author{
John STEELE \\ Grand Canyon University \\ Phoenix, Arizona, USA \\ Eric J. NORDIN \\ Grand Canyon University \\ Phoenix, Arizona, USA \\ Elizabeth LARSON \\ Grand Canyon University \\ Phoenix, Arizona, USA \\ Daniel MCINTOSH \\ Arizona State University \\ Tempe, Arizona, USA
}

\section{ABSTRACT}

The purpose of this study is to examine the impact of information placement within the confines of the online classroom architecture. Also reviewed was the impact of other variables such as course design, teaching presence and student patterns in looking for information. The sample population included students from a major online university in their first year course sequence. Students were tasked with completing a survey at the end of the course, indicating their preference for accessing information within the online classroom. The qualitative data indicated that student preference is to receive information from multiple access points and sources within the online classroom architecture. Students also expressed a desire to have information delivered through the usage of technology such as email and text messaging. In addition to receiving information from multiple sources, the qualitative data indicated students were satisfied overall, with the current ways in which they received and accessed information within the online classroom setting. Major findings suggest that instructors teaching within the online classroom should have multiple data access points within the classroom architecture. Furthermore, instructors should use a variety of communication venues to enhance the ability for students to access and receive information pertinent to the course.

Keywords: Information placement, classroom design, online classroom, student preference.

\section{INTRODUCTION}

Student engagement is a vital element in determining student achievement and success in the online classroom (Handelsman, Briggs, Sullivan \& Tower, 2005; Wei, Chen, \& Kinshuk 2012). With the continued growth of online education across the world, it is important for educators to gain an understanding of the impact of student's interactions with course content as it directly affects student learning and engagement (Murray, Pérez, Geist, Hedrick, \& Steinbach, 2012). However, what precedes the ability of students to be able to be engaged in the learning 
process of the online classroom is that students must first be able to find the critical information that allows them to be successful in the course. Where students look for, find, and ultimately choose whether or not to utilize the information is intertwined with other elements such as course design, teaching presence, and instructor information placement. Recent advances in technology only serve to magnify the urgency in garnering further understanding of the ideal ways to deliver course materials to better support the learning process (Murray et al., 2012).

\section{COURSE DESIGN}

Course design is one element of the information searching process that needs to be included when regarding information placement in the online classroom. Instructors are often not included in the design process which is why information placement can be critical to student's success. Kamlaskar and Killedar (2015) discussed how many schools have developed a "Teaching-Learning Process" model that consists of many components, but most notably is the delivery of information element. Additionally, when designing any online learning curriculum, there comes a choice of what elements to include that will engage the learner. Lister (2014) analyzed 17 studies on course design derived from 14 different peer-reviewed educational technology journals, to attempt to identify patterns or common themes that could emerge from the studies regarding e-learning and online courses. The findings of analysis suggested four major themes in the design of online courses: 1) course structure 2) content presentation, 3) collaboration and interaction and 4) timely feedback. Consequently, regardless of the course design instructors can control the content presentation, timely feedback, and interactions (Lister, 2014).

One study investigated the student's patterns of accessing course content and other materials to support the learning process and found that the increased access and convenience are often the most selected reasons for placement (Murray et al., 2012). Another study confirmed this by determining that the ease of navigation and course design are prominent predictors of the ability for a positive e-learning experience (Salyers, Carter, Carter, Myers, and Barrett, 2014). A common result emerged from the studies determined that many online students have busy lives and want the easiest route to course material. Knowing this, it becomes crucial for instructors to make the pertinent class materials easy for students to access. Finally, evidence from studies has denoted that in effective, well-designed online courses where engaging interactions occur between teachers, students, and content, students have been able to outperform students in comparable face-to-face classes (Salyers et al., 2014).

Teaching Presence

Garrison, Anderson, and Archer (2000) found that learning occurs in a community through three core elements of teaching presence, social presence, and cognitive presence that form the Community of Inquiry. Instructors can use teaching presence to set clear expectations as to where students can find relevant information. One suggestion is to set the tone for the class by planning the first exercise. Kamlaskar and Killedar (2015) explain how the objective of the first exercise is to build confidence in the teacher by displaying that the teacher is supportive, engaged, approachable and available. It also allows the teacher to set clear expectations as to where students can find certain valuable materials in the online classroom such as the syllabus, additional instructions, multimedia and other necessary resources.

An analysis of 17 different studies identified content presentation and interaction as the crucial elements in designing online courses (Lister, 2014). However, these items can also relate to a strong teaching presence component as well. The analysis indicated that students preferred a choice in content which could include a selection of the presentation of content such as posting information in various places in the online classroom to give students choices. Murray et al., 
(2012), found that students reported a tendency only to retrieve content that directly correlated to them receiving a good grade, or that was perceived to be necessary to complete the course. Hence, it becomes of extreme importance for instructors not to bombard students with unnecessary content. Also, Murray et al., (2012) determined that students in the online environment are often limited to time constraints causing students to access the materials that they perceive as useful. Thus, it becomes imperative for instructors to place pertinent information in places where students are most likely to access them.

Additionally, the study confirmed the importance of students being able to find educational materials to achieve the preferred learning results (Brown \& Voltz, 2005; Murray et al., 2012). Students reported the propensity to repeat their access to course content while continuously finding content that they determined tied directly to their course outcome (Murray et al., 2012). This further solidifies the importance of instructors in ensuring that students understand where they can find the content necessary to help them be successful. Finally, the placement, modality and delivery of information become a vital piece of ensuring student success.

\section{Instructor Information Placement}

One of the most important aspects of communicating information to students within the online classroom is the instructor's introduction to students into the classroom (Joyner et al., 2014). An effective modality to send this welcoming message as noted by (Glikson, \& Erez, 2013) is by the course email system. The welcome message can either be accomplished through communicating with the student via a message sent through some in class email system or a student personal email account. Welcoming new students to an online course can help alleviate preconceived notions that the online classroom is an unwelcoming and esoteric space in which students will have little, if any, interaction with their instructor (Gedera, 2014). The welcoming message can serve as an area to introduce students to the expectations of the course, directions for assignments, as well as provide insight on how to access materials related to the course (Ryman, Burrell, \& Richardson, 2009). As deNoyelles, Mannheimer Zydney, and Baiyun (2014) indicated, an instructor introduction can provide information about classroom behaviors, set the tone for relationships, and communicate classroom policies to students. The welcoming email message should provide both supportive and instructional information to help students familiarize themselves with the class and develop a sense of belonging (Ryman et al, 2014). At an optimal level, an effective introduction provided by the instructor can relieve student fear, develop a positive rapport, and lessen the instructor workload concerning questions relating to accessing information throughout the duration of the course.

Providing ongoing communication is another important aspect of information communication as indicated by the literature. Joyner et al. (2014) indicated ongoing communication is crucial for providing updates about the class, where to access newly uploaded information, and general updates relating to course progression and student progress. The use of discussion forums or other asynchronous public forums within the online classroom provide an efficient area for instructors to communicate continually with their students (Stone \& Chapman, 2006). Ongoing communication has the potential to increase student engagement in the class, which could help increase student success and lessen attrition rates. Delivering additional content is a critical function of ongoing communication (Stone \& Chapman, 2006). Ongoing communication can help the instructor include content that meets the students' needs as the instructor increase his or her understanding of student informational needed, which, in turn, helps the instructor localize informational context and deliver to the proclivities of students. 
The individualization of information is critical toward increasing viewership as students are increasingly demanding a personal approach to online learning (Gallien, \& Oomen-Early, 2008). By personalizing information, instructors can increase the level of engagement with students that can induce an edifying dialogue about the course between the instructor and student (Ryman et al., 2009). Providing ongoing communication can help lessen many of the obstacles presented to the instructor in the online classroom setting and create a more edifying and friendly milieu for online students, which has the potential to increase the effective transfer of information within the online classroom environment.

The third important aspect of providing information to students within the online classroom setting entails the guidance provided by instructors. As the online classroom can be a complex and confusing environment for students. Thus, the promptness of instructors' response to student questions about information is important. Byron (2008) indicated instructors should respond to the question posed by students within 48-72 hours. Responding to student questions promptly, allows instructors to lessen the confusion students might have as well as provide guidance about how to access information about the course to decrease the need for future questions (Skinner, 2007). Creating learning communities in which students support one another and provide information is another route to providing effective information communication. Instructors can help create peer-to-peer learning areas where students both post and answer questions concerning information about the course (Ryman et al., 2009). By establishing and encouraging the use of peer-sharing areas, instructors form a sharingoriented environment. As Brindley, Walti, and Blaschke (2009) noted, part of the process of guidance within the online classroom setting is creating an atmosphere in which communication, collaboration, cooperation, and community can develop. The effective guidance provided by instructors can help students feel comfortable in asking questions, encourage students to ask each other questions, as well as develop a milieu in which question students proactively seek out information about the class rather than being passive consumers.

Although the architecture of various online classrooms can and do vary, using the communicational tools embedded within the Learning Management Systems (LMS) can help instructors convey information to students in an effective manner. Most online classrooms have an intercourse email system, which allows instructors to contact students directly and privately, and instructors can use this feature in their efforts to communication information (Byron, 2008). As deNoyelles et al. (2014) indicated, students tend to be receptive and are likely to view emails sent directly to them as they feel there is a personalization of the information included in the email. Communication to the entire class, conversely, can require a different use of communicational tools in the online classroom setting. Skinner (2007) asserted that discussion forum areas in which communication is open to all students could be an effective area to provided general information pertinent to the course. This avenue of communication affords instructors the opportunity to provide course-wide information, without the need to contact students individually (Fullick, 2006). The effective use of the communicational tools provided within the LMS can allow instructors to communicate valuable information easily to students within a public forum that accessed easily and frequently by students, increasing the likelihood of students viewing and acting upon the information provided. 


\section{METHODOLOGY}

The purpose of this study is to determine the ideal locations for placing classroom materials for optimum student view. The framework of the study used qualitative research methodologies. The study was undertaken to answer two specific research questions. The following are the two research questions for this study:

R1: Where do students look for information in the online classroom?

R2: What is the optimum location for instructors to place pertinent information?

A six-question survey was created to answer these questions using SurveyMonkey. The questions were designed to identify the informational access points used by students within the confines of the online classroom architecture. In the first question, students indicated in which course they were enrolled. The other five questions were open-ended questions that sought to provide a critical evaluation of where students go in the online classroom. Due to the open-ended nature of the questions, students had the ability to provide multiple answers (or informational access points) to each question.

The target population included students from three classes in the first year sequence of undergraduate courses from one small university in the Southwestern United States. Of the 72 students invited to take part in the survey, 43 responded, amounting to a $59.7 \%$ response rate as noted in Table 1.

Table 1. Participatory Data

\begin{tabular}{lcc}
\hline Section & Total students in class & $\begin{array}{l}\text { Number of } \\
\text { students who took } \\
\text { the survey }\end{array}$ \\
\hline Class \#1 & 26 & 13 \\
Class \#2 & 23 & 13 \\
Class \#3 & 23 & 17 \\
\hline
\end{tabular}

\section{RESULTS}

The results of the survey indicated that students prefer to receive information from multiple sources within the classroom architecture, and will access information in multiple areas within the classroom setting. Students, according to the survey results, were satisfied with the current ways in which they received and accessed information within the classroom setting. However; one possible reason for preferring various information receiving and accessing areas relate to the diversity of the online student population, were competencies regarding online classroom technology as well as familiarity with the classroom setting are diverse (Kuo, Walker, Belland, \& Schroder, 2013). Many online students also have experience with multiple LMS platforms, which might contribute to a wide array of preferences (Dykman, \& Davis, 2008). The primary purpose behind why a student is searching for information and how they prefer to receive information can depend on the motivations and reasons for searching or receiving information. Examples as such, include motivations, and other causes can include grading feedback, classroom policies, interacting with their peers or instructors, and wanting information about upcoming assignments (Murray et al., 2012).

Interwoven in the section below are selected and representational responses from students to provide a more genuine example of student needs and wants concerning accessing and receiving information in the online classroom setting. Students provided the material in the survey that are paraphrased in the section below. Moreover, students received an indicator of S1-S43, as there were 43 students responded to the survey. This information could help 
provide a more in-depth and personalized narrative of students' thoughts about receiving and accessing information.

Question four of the survey asked students where they looked for information about the course within the classroom, and there are two main access points students sought to find information related to the course. Twenty-five students identified that the course materials tab was their primary access point for information. For this study's purposes, course materials tab is the place where the majority of instructional material (lectures, assignment details, additional reading materials) that are separate from the syllabus. The syllabus closely follows the course materials tabs as $41.07 \%$ of the participants indicated the syllabus was where students primarily looked for information. S5 and S9 indicated the syllabus was the first place to search for information about the course. Possible reasons behind the syllabus being the most common area to find information are that the syllabus is a familiar source of information for a student in both online and ground-based classrooms, students find they have easy access to the syllabus, and that the syllabus provides a rich source of information. S1 and S23 noted, the syllabus was easy to access within the classroom, and this was one of the first places they sought information during the class. The majority of students indicated the syllabus was a useful asset to gain information and helped them have a better understanding of the course as identified in Table 2.

Table 2. Where do you look for information about the course in the classroom?

\begin{tabular}{lll}
\hline Information Access Point: & \# of Students & Response rate \\
\hline Course Materials & 25 & $44.64 \%$ \\
Syllabus & 23 & 41.07 \\
Calendar & 2 & $3.57 \%$ \\
Forums & 2 & $3.57 \%$ \\
Announcements & 1 & $1.79 \%$ \\
GCU Library & 1 & $1.79 \%$ \\
Internet & 1 & $1.79 \%$ \\
None & 1 & $1.79 \%$ \\
\hline Grand Total & 56 & $100.00 \%$ \\
\hline
\end{tabular}

The results of the survey indicated that students preferred to access the discussion forum area of the online classroom when first logging into the site. Over $39 \%$ of respondents indicated the discussion forum was their first destination when logging into the classroom. One possible reason for this is students receive participation points for posting responses to discussion questions as well as responding to student and instructor posts. Thus, there is a grade-based motivation for entering and participating in the discussion forums. The discussion form is also where interaction between students and the instructor occurs (S2, S4, S8, S17, S26, S33), which might be a source of motivation for entering the discussion forum upon initial entry into the classroom (Brindley et al., 2009). Discussion forums provide a chance for dialogue and peer-to-peer learning as well (deNoyelles et al., 2014). As S39 noted, the first place they accessed when entering the classroom was the discussion forum as it allowed them to interact with their fellow students. Areas that allow students the ability to interact with one another are popular and accessed extensively (Gedera, 2014). A salient and actionable result from this portion of the study could be that placing information in areas in which students' first access when entering the online classroom can increase the likelihood of viewership. Response rates for the primary access points are provided in Table 3. 
Table 3. What is the first area in the classroom you go to when you log in?

\begin{tabular}{lll}
\hline Primary Access Point & \# of Students & Response rate \\
\hline Forums & 19 & $39.58 \%$ \\
Calendar & 13 & $27.08 \%$ \\
Gradebook & 7 & $14.58 \%$ \\
Announcements & 4 & $8.33 \%$ \\
Syllabus & 2 & $4.17 \%$ \\
Resources & 2 & $4.17 \%$ \\
Assignments & 1 & $2.08 \%$ \\
\hline Grand Total & 48 & $100.00 \%$ \\
\hline
\end{tabular}

The results of the survey further indicated that the discussion forum area of the online classroom was the area students frequented. At a $58.70 \%$ response rate, overwhelmingly those surveyed indicated the discussion forum was the area of the classroom they visited most frequently. 529 stipulated that the discussion forum is the area they most often visited because this was the area in the classroom they could interact and create connections with their instructor and classmates. Brindley et al. (2009) noted the students tend to participate in discussion forums or other areas of that provide space to interact with their classmates as this helps to lessen the sense of isolation frequently felt by online students. The responses of S10, S14, S18, S24, S31, and S42 who specified the discussion forum allowed them to perceive a sense of connection with their classmates and made the impersonal nature of the online milieu less intimidating and more individualized. The discussion forum, based on the results of the survey, can provide a rich area for information placement as students tend to access this area both when first entering the online classroom and visit this area most frequented as compared to other venues in the online classroom. Response rates for the area of classroom frequented most by students appear in Table 4.

Table 4. What area of the classroom do you frequent most often?

\begin{tabular}{lll}
\hline Classroom Area: & \# of Students & Response rate \\
\hline Forums & 27 & $58.70 \%$ \\
Gradebook & 7 & $15.22 \%$ \\
Calendar & 5 & $10.87 \%$ \\
Resources & 3 & $6.52 \%$ \\
Syllabus & 2 & $4.35 \%$ \\
Course Materials & 1 & $2.17 \%$ \\
Assignments & 1 & $2.17 \%$ \\
\hline Grand Total & 46 & $100.00 \%$ \\
\hline
\end{tabular}

Deciphering the modality to send information to students in the online classroom is an important aspect of the online instructors' job, and the results from the survey indicated that e-mail was the optimal modality for how students preferred to receive information about the course. Of those surveyed, $36 \%$ reported that e-mail was the preferred method for receiving information about the course. As S22 noted, receiving e-mails about course information would ease the process of searching for information. One of the main reasons for the e-mail preference is the familiarity students have of receiving information through e-mail as indicated by $\mathrm{S10}$ and $\mathrm{S} 20$ responses about receiving an e-mail to a personal e-mail address. Both students also mentionedhow this would be useful as this would cut down on the number of areas one would need to search for information. Sending e-mails can additionally allow instructors to contact students even when students do not log into the classroom, as S8, S11, and S24 noted, receiving information about the class in close to real-time could be helpful to understand in a more acute manner the class as well as the obligation of the course. The results of the survey indicated that students want to receive information about the class in a form 
they find convenient, familiar, and that allows them to receive information immediately. Response rates for student preference on receiving information are provided in Table 5.

Table 5. How would you like to be notified about information in the classroom?

\begin{tabular}{lll}
\hline Information Access Point & \# of Students & Response rate \\
\hline Email & 18 & $36.00 \%$ \\
Forums & 11 & $22.00 \%$ \\
Text Message & 6 & $12.00 \%$ \\
No Change & 6 & $12.00 \%$ \\
Pop Up & 5 & $10.00 \%$ \\
Announcements & 3 & $6.00 \%$ \\
Calendar & 1 & $2.000 \%$ \\
\hline Grand Total & 50 & $100.00 \%$ \\
\hline
\end{tabular}

The final and perhaps most curious result indicated by the survey was students tended to be satisfied with the current information location and delivery systems in the LMS platform. Responses to the question on the desired location for information placement within the online classroom architecture showed that $38.10 \%$ were content with the current design of the LMS. S4, S5, S6, S7, S8, S12, S13, S20, S25, S29, S32, S36, and S41 all stipulated they were happy with the existing architecture of the classroom concerning how they accessed and received information. One probable reason for this result is students who participated in the survey did not have experience with other LMS and did not have a comparison system to judge against their current system. Students may have also not fully understood the nuances behind online LMS, which might bias responses based on unfamiliarity. An additional possible reason for this result is students who participated in the survey did so during the last week of the course, and they may have grown accustomed to the features of the system as well as believed that no changes where necessary to improve information receiving or information access. As Ryman et al. (2009) noted, gaining familiarity with an online learning platform could help students to become more comfortable operating within the platform. A critical result from the survey might be that students are adaptable and willing to learn about the particulars of online classroom design, but familiarity with the system is paramount. In addition, creating principles within the classroom design could help the process of having students learn to navigate the system to receive and access information in an efficient manner.

\section{DISCUSSION}

The results of the study indicated that students prefer to access information in different areas as well as receive information in different settings, but in general were satisfied with their current classroom's architecture. These findings can have a positive effect on how instructorsteaching online courses place information within the classroom to promote increased viewership by students. The syllabus was the main area students sought to access information about the course, and the result was not surprising given the familiarity most students have with the concept of a syllabus. From the instructors' perspective, this result should prompt them to direct students to the syllabus at the beginning of the course and to review the syllabus continually as the course progresses (Gedera, 2014). Possible strategies to accomplish this are to post reminders about the syllabus within the discussion forum, post information generated from the syllabus in the discussion forum, and send e-mails to students reminding them to access the syllabus. These strategies could potentially relieve the confusion many students have regarding the requirements of the course. The discussion forum, as stipulated by the survey results, was the area in which online students first accessed when entering the classroom and was the area students visited most frequently. Instructors teaching online courses could use these findings to employ the discussion forum as a vehicle 
to communication information in an effective manner to their students. Information placed in the discussion forum could include external information the instructor wishes to include in the course, information about classroom policies, procedures, and expectation, as well as any changes or events occurring during the progression of the course (Brindley et al., 2009). The students who participated in the study indicated that receiving e-mails about course information was another primary modality of communication. As such, instructors can use this modality - often embedded within the architecture of the online classroom - to communication with students. E-mail communication with students can help create a sense of personalization, open an arena for dialogue between the instructor and the student, as well as encourage students to contact their instructors when regarding questions or concerns pertaining to the course. Receiving an e-mail from the instruction could additionally help students feel less isolated in the online classroom setting (Joyner et al., 2014). The results from the study additionally indicated that student familiarity with the online classroom was an important aspect of information accessing and receiving the majority of students stipulate they are satisfied with the features of their current classroom. Instructors can help to improve information accessing and receiving by ensuring students have a full understanding of the various communication features within the online classroom.

The findings of the study found that students expressed desire in having course information delivered to them through multiple electronic means, with the majority of them favoring having information sent through e-mail. Although this contradicts Lenhart, Ling, Campbell, and Purcell's (2010) research that suggested students are moving away from e-mail as their primary communication tool, e-mail is an effective information delivery method for students in an online learning environment. Traditionally students receive a school e-mail, which instructors can use to send reminders and other pertinent information. Furthermore, McAnally, Espinsoa-Gomez, and Lavigne (2011) found that instructors favored the use of e-mail as a communication tool in online classrooms. When instructors use the communication strategy that they are most comfortable with, it can lead to higher student-teacher interaction (McAnally et al., 2011).

Further analysis of the data revealed that student preference on information placement centered on the usage of technology. Imran, Ahmad, and Mushta (2012) noted that with the advent of technology, successful online course design offers opportunities to tailor education to a student's needs. In addition, students in online learning courses tend to be digitally literate and need access to information in a conveniently digitized manner. These type of students would benefit from having access to information via innovative technology tools.

One effective Web 2.0 tool for information delivery is the Remind (formerly Remind 101) App. With the Remind App, students can sign up to receive pertinent information from their instructor via text message. Online instructors can use the Remind App to send out information updates, reminders of upcoming tests, or even to send out helpful tips and hints on the homework assignment. The Remind App is an effective method of information delivery as Troung (2010) noted that over $\mathbf{9 9 . 8 \%}$ of college students own one or more mobile phones, and over $97 \%$ used short message service (SMS) as their main method of communication. Bobbitt, Inman, and Bertran (2013) theorized that if students are moving to a mobile means of communication, instructors should think of using text messages to communicate with their students, as it is a more reliable and rapid delivery method. Research shows students who have used the Remind App prefer it for communication purposes and wanted other instructors to use the service (Bobbitt, Inman, \& Bertran, 2013).

Students can also benefit from having information delivered through multimedia content. Jonasses (2003) defines multimedia as the usage of multiple forms of media, 
including text, graphics, animation, videos, and pictures (as cited in Surjono, 2015). Surjono (2015) found students had higher achievement scores in their online electronics course when using their multimedia preferences and learning styles. One multimedia platform instructors can use for course information is Moovly. Moovly is an online tool that allows the user to create personalized multimedia content. Instructors create personalized information through animated objects, videos, voice, music, and add them to a timeline interface, allowing for simple multimedia-based videos and presentations. Once the information has transferred into a Moov (Moolvy's multimedia format), an instructor can upload it into the architecture of the online classroom or have students access the multimedia content through a web link.

\section{LIMITATIONS}

There are limitations to this study that need acknowledgment, several of which offer future research opportunities. First, the basis of the research was unique to the student population in higher education. All the research participants are in their first-year sequence, and as a consequence, are still learning how to navigate the learning management system. Future work would benefit from administering the study to those students who are in their second, third, or fourth-year sequence.

A second limitation relates to course design as all the research participants were from one specific critical thinking course. This specific course implies a possibility of the limitation of the generalizability of results. Additional courses across different disciplines could have increased the response rate and provided a stronger argument on generalizability.

Finally, the study did not address the different needs students may have while taking an online course. It did not look at their level of familiarity with technology, type of system used, nor learning style. Future research should address multiple platforms of technology as well as identify how familiar a student is with navigating the architecture of an online learning management system.

\section{CONCLUSION}

The students who participated in this study indicated they prefer to access and receive information in multiple areas, want instructors to use emerging communication technologies to connect with them, use multimedia technologies in the classroom as a form of communication, but were satisfied in general with how they received and accessed information in their current classrooms. These findings could have profound effects for how instructors in online courses communicate information to their students. Instructors should make use of the multiple communication modalities embedded within the classrooms to increase the likelihood of student viewership as students tend to access information in multiple areas. Students prefer to receive information from instructors in different regions of the classroom, and using the different areas will help instructors communicate with their students in a more effective manner. Online students in this study indicated that they would prefer their instructors to use multiple means of communication (i.e. texting, e-mail, message boards) when conveying information, and enjoy the use of multimedia technologies for information dissemination. Instructors in the online classroom have multiple modalities to communicate information. The results indicated instructors should use these communication venues, especially the ones embedded in the course, to enhance the ability for students to access and receive information pertinent to the course. 


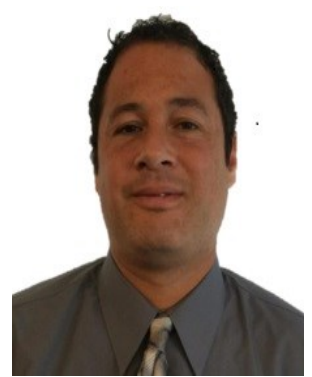

John STEELE is an Assistant Professor who teaches Critical Thinking, University Introduction, and Psychology classes at Grand Canyon University. He is a certified K-12 School Counselor, certified elementary teacher, and has taught Adjunct Education at Phoenix Community College and at GCU. He is a GCU Alumnus, with a Master's in Education in School Counseling and a Master's of Science in Psychology. John is currently pursuing his doctoral degree in General Psychology with an emphasis in Integrating Technology, Learning, and Psychology at GCU. John's professional interests include research in online learning and academic integrity.

John STEELE

College of Humanities and Social Sciences

Grand Canyon University, 3300 W. Camelback Road

Phoenix, AZ, United States 85017

Phone: 602-639-7742

E-mail: john.steele@gcu.edu

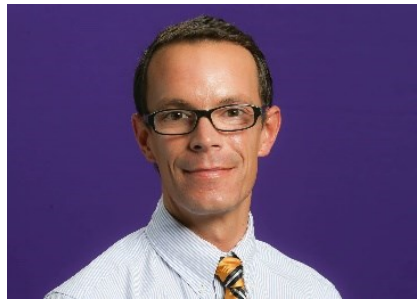

Dr. Eric J. NORDIN is a Faculty Member in the College of Doctoral Studies at Grand Canyon University. In this role, he teaches research and businesses courses, with an emphasis in management and marketing. He received his doctorate in Business Administration from Walden University in June 2013, with a dissertation entitled Exploring Effective Communication for Organizational Change. His research interests include online education, change communication, business communication, and organizational development. Dr. Nordin has published numerous articles in peer-reviewed journals, presented at serval academic conferences, and contributed to a doctoral-level textbook concerning the research process.

Dr. Eric J. NORDIN

College of Doctoral Studies,

Grand Canyon University, 3300 W. Camelback

Road Phoenix, AZ, United States 85017

Phone: 602-639-8180

E-mail: eric.nordin@gcu.edu

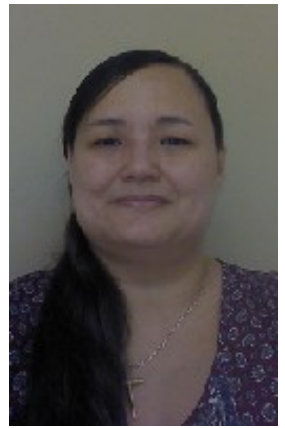

Elizabeth LARSON is an Assistant Professor at Grand Canyon University, in the College of Humanities and Social Sciences. She holds a Master's of Education in Secondary Education as well as a Master's of Science in Psychology, and is pursuing a Doctor of Philosophy in General Psychology with an Emphasis in Industrial and Organizational Psychology. Her goal is to help organizations understand the impact PTSD has on job performance from a caregiver's perspective. She has published several articles in peer-reviewed journals, contributed to an undergraduate textbook, as well as presented at several conferences. Her research interests include cognitive science and the philosophy of technology.

\section{Elizabeth LARSON}

College of Humanities and Social Sciences

3300 W. Camelback Road Phoenix, AZ 85017

Phone: 602-639-6256

Email: elizabeth.larson@gcu.edu 


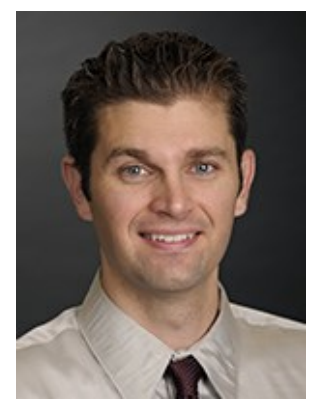

Daniel MCINTOSH is a Lecturer in the W.P. Carey School of Business at Arizona State University teaching courses in Marketing Research, Sports Management and Sports Analytics. He works across disciplines teaching course in the Sports Law and Business program with the Sandra Day O'Connor Law School. He is also President of Cardinal Advising, a consultancy that has worked with the NBA and STATS LLC to identify indicators of fatigue in player tracking data. Prior to joining ASU, Daniel was an instructor of Mathematics and Marketing at Grand Canyon University for 5 years. Daniel is an ASU undergraduate alum and a graduate of the W.P Carey MBA Sports Business program. He is also a graduate from the Barrett Honors College.

\section{Daniel MCINTOSH}

Arizona State University | W. P. Carey School of Business | Lecturer Address: 300 E. Lemon St., BAC 478 | Tempe, AZ 85287

Phone: 480.727.9476

Email: Daniel.McIntosh@asu.edu

\section{REFERENCES}

Brindley, J. E., Walti, C., \& Blaschke, L. M. (2009). Creating effective collaborative learning groups in an online environment. International Review of Research in Open and Distance Learning, 10, 1-18.

Brown, A., \& Voltz, B. (2005). Elements of effective e-learning design. The International Review of Research in Open and Distance Learning, 6(1). Available from http://www.irrodl.org/index.php/irrodl/article/view/217

Byron, K. (2008). Carrying Too Heavy a Load? The Communication and Miscommunication of Emotion by Email. The Academy of Management Review, (2). 309-327.

Bobbitt, R., Inman, R., \& Bertrand, E. (2013). Using Remind 101 as a Classroom: Communication Tool. NACTA Journal, 57(4), 77-78.

deNoyelles, A., Mannheimer Zydney, J., \& Baiyun, C. (2014). Strategies for creating a community of inquiry through online asynchronous discussions. Journal of Online Learning \& Teaching, 10(1), 153-165.

Dykman, C. A., \& Davis, C. K. (2008).The shift toward online education. Journal of Information Systems Education, 19, 11-16

Fullick, P. L. (2006). Synchronous web-based communication using text as a means of enhancing discussion among school students. Campus-Wide Information Systems, 23(3). 159-170.

Gallien, T., \& Oomen-Early, J. (2008). Personalized versus collective instructor feedback in the online courseroom: Does type of feedback affect student satisfaction, academic performance and perceived connectedness with the instructor?. International Journal on E-Learning, $7(3), 463-476$.

Garrison, D. R., Anderson, T., \& Archer, W. (2000). Critical inquiry in a text-based environment: Computer conferencing in higher education. The Internet and Higher Education, 2(2-3), 87-105. 
Gedera, D. P. (2014). Students' experiences of learning in a virtual classroom. International Journal of Education \& Development Using Information \& Communication Technology, 10(4), 93-101.

Glikson, E., \& Erez, M. (2013). Emotion display norms in virtual teams. Journal of Personnel Psychology, 12(1), 22-32. doi:10.1027/1866-5888/a000078

Handelsman, M.M., Briggs, W.L., Sullivan, N. and Towler, A. (2005). A measure of college student course engagement. The Journal of Educational Research, 93(3), 184-191.

Imran, S. M., Ahmad, H., \& Mushtaq, M. (2012). Design and Pedagogy Features in Online Courses: A survey. Trends in Information Management, 8(1), 9-22.

Joyner, S. A., Fuller, M. B., Holzweiss, P. C., Henderson, S., \& Young, R. (2014). The importance of student-instructor connections in graduate level online courses. Journal of Online Learning \& Teaching, 10(3), 436-445.

Kamlaskar, C.H., \& Killedar, M. (2015). Design and delivery of online courses in YCMOU. Turkish Online Journal of Distance Educaiton (TOJDE), 16(2), 137-150.

Kuo, Y., Walker, A. E., Belland, B. R., \& Schroder, K. E. (2013). A Predictive study of student satisfaction in online education programs. International Review of Research in Open \& Distance Learning, 14(1), 16-39.

Lenhart, A., Ling, R., Campbell, S. and Purcell, K. (2010, April 20). Teens and mobile phones. Pew Internet and American Life Project. Retrieved from http://pewinternet.org/Reports/2010/Teens-and-Mobile-Phones.aspx

Lister, M. (2014). Trends in the Design of E-Learning and Online Learning. Journal of Online Learning \& Teaching, 10(4), 671-680.

McAnally-Salas, L., Espinosa-Gomez, E. J., \& Lavigne, G. (2011). With Tools and Strategies Teachers Use in Online Courses: A Mexican Public University Case. Online Submission, US-China Education Review v8 n3 p276-287.

Murray, M., Pérez, J., Geist, D., Hedrick, A., \& Steinbach, T. (2012). Student Interaction with Online Course Content: Build It and They Might Come. Journal of Information Technology Education, 11, 125-140.

Ryman, S., Burrell, L., \& Richardson, B. (2009). Creating and sustaining online learning communities: Designing environments for transformative learning. International Journal of Pedagogies \& Learning, 5(3), 46-58.

Salyers, V., Carter, L., Carter, A., Myers, S., \& Barrett, P. (2014). The Search for Meaningful eLearning at Canadian Universities: A Multi-Institutional Research Study.

International Review of Research in Open \& Distance Learning, 15(6), 313-337.

Skinner, E. (2007). Building knowledge and community through online discussion. Journal of Geography in Higher Education, 31(3), 381-391

Surjono, H. D. (2015). The effects of multimedia and learning style on student achievement in online electronics course. Turkish Online Journal of Educational Technology, 14(1), 116-122. 
Stone, S. J., \& Chapman, D. D. (2006). Instructor presence in the online classroom. Online Submission.

Truong, K. (2010). Student smartphone use doubles; instant messaging loses favor. Wired Campus. Retrieved from http://chronicle.com^^logs/wiredcampus/studentsmartphone-use-doubles-instant-messaging-loses-favor/24876

Wei, C., Chen, N., \& Kinshuk. (2012). A model for social presence in online classrooms. Educational Technology Research \& Development, 60(3), 529-545. doi:10.1007/s11423-012-9234-9 